\title{
Tratamientos Biológicos del Autismo y Dietas de Eliminación
}

\author{
MIGUEL HIGUERA C. ${ }^{1}$ \\ 1. Fonoaudiólogo. Lic. Universidad de Chile. \\ Magíster en Educación Superior. Universidad Mayor. \\ Docente Asociado, Escuela de Fonoaudiología. Universidad Mayor.
}

\begin{abstract}
\section{Biological Treatments of Autism, Elimination Diets. A Critical Review}

This paper presents some critical considerations regarding the growing adoption, by families, of alternative treatments and diets for the treatment of various disorders like autism in children. Research does not seem to support such practices, with the exception of the relationship between timesoral and vaccines, neurological and cardiac disorders. Issues to consider are pointed out in the need to opt for biological treatments, and the need for families and research teams to work together for the purpose of clarifying such procedures.

(Key words: Development disorders, elimination diet, timerosal, candidiasis, immunization, gluten, casein). Rev Chil Pediatr 2010; 81 (3): 204-214
\end{abstract}

\section{RESUMEN}

El objetivo de este trabajo es presentar consideraciones críticas en relación a la creciente adopción, por parte de las familias de niños con trastornos del desarrollo, de tratamientos alternativos y dietas para reducir los síntomas de diversas alteraciones tales como el autismo, SDAH y otros. Las investigaciones no parecen apoyar tales prácticas, a excepción de la creciente evidencia de la relación entre el timerosal de las vacunas y afecciones cardíacas y neurológicas. Se señalan los elementos a tener en cuenta para optar por los tratamientos biológicos y dietas, junto con insistir en la necesidad de mancomunar esfuerzos entre familias y equipos de investigación para desarrollar estudios que clarifiquen los efectos de tales procedimientos.

(Palabras clave: Trastornos del desarrollo, dietas de eliminación, timerosal, candidiasis, vacunas, gluten, caseína).

Rev Chil Pediatr 2010; 81 (3): 204-214

Trabajo recibido el 28 de julio de 2009, devuelto para corregir el 25 de agosto de 2009, segunda versión el 26 de agosto de 2009, aceptado para publicación el 18 de enero de 2010.

Correspondencia a:

Miguel Higuera C.

E-mail: mhigueracancino@yahoo.es 
El presente trabajo tiene como propósito fundamental, entregar información general acerca de la línea de tratamientos biológicos que ha comenzado a desarrollarse a partir de algunos trabajos en EE.UU. e Inglaterra. Fundamentalmente, señalaré algunos elementos básicos para entender de modo general esta visión, junto con aportar algunos elementos críticos al momento de optar o no por la aplicación de esta visión a la terapia de niños/as con trastornos profundos del desarrollo (TPD), Síndrome de Déficit Atencional Hiperactivo (SDAH) y otros.

Previo al desarrollo del tema en particular, quisiera señalar que ha sido realizado desde una doble perspectiva: como terapeuta de lenguaje especializado en trastornos del desarrollo (TDD) y como padre de un niño autista, por lo que su difusión me parece necesaria a los especialistas para tomar en cuenta la perspectiva de las familias que necesitan ser informadas respectos de los tópicos que se expondrán.

\section{Generalidades y Bases de los Tratamientos Biológicos en TPD}

Desde hace un tiempo, algunas investigaciones han venido señalando las posibles relaciones entre la alimentación y una serie de trastornos que van desde las alergias, las intolerancias alimenticias y, últimamente, los efectos opiáceos de algunos componentes del trigo y la leche de vaca o cabra.

Ya en la década de los sesenta, el inglés Bernad Rimland ${ }^{1}$, fundador del instituto para la investigación del Autismo, se manifestaba acerca de la posible relación entre deficiencias alimentarias y algunos síntomas conductuales de los niños dentro del espectro autista.

En los últimos diez años, diversos estudiosos del tema, tanto en Europa, como en EEUU, han podido precisar algunos elementos importantes que merecen ser considerados al momento de realizar una intervención terapéutica en niños que presentan trastornos del desarro1lo dentro del espectro autista, e incluso, en el cuadro de Déficit Atencional.

Específicamente, las principales evidencias apuntan a los siguientes factores:

\section{Probable Acción de Opiáceos externos}

La leche de vaca y de cabra, junto con el del trigo, el centeno y la cebada, poseen ciertas proteínas (caseína y gluten), cuya estructura o partes de esta, al no ser digeridas completamente, presentan propiedades opiáceas (como la morfina). La mayoría de las personas logra degradar estas moléculas en el lumen del intestino delgado, y conceptualmente no ingresan al torrente sanguíneo, aun cuando en algunas personas podrían generar una respuesta inmune, con generación de anticuerpos o células dirigidas contra componentes de dichas proteínas. Por otra parte, tanto los intestinos, como la red de vasos sanguíneos que irrigan el cerebro (barrera hematoencefálica) impiden el paso de estas proteínas al cerebro, por lo que es muy difícil que moléculas tan grandes logren penetrar tales barreras ${ }^{2}$.

Sin embargo, se ha propuesto que en la población de niños autistas, existiría una mayor tendencia a presentar errores del metabolismo que impiden degradar esas moléculas y/o presentan mayor permeabilidad en las barreras naturales, por lo que esas morfinas externas (exorfinas) llegarían a sitios del cerebro que se relacionan con el desarrollo del lenguaje, la comunicación, las relaciones sociales y la modulación de sensaciones y percepciones (lóbulos frontales, temporales, parietales), alterando el funcionamiento de todos los procesos implicados en la cognición y la comunicación ${ }^{3}$.

Según lo que las familias informan, muchos niños afectados comienzan a manifestar tales problemas al momento del cambio de alimentación (18-24 meses), por lo cual se sugiere una intervención alimentaria temprana, puesto que el efecto de las exorfinas sería de tipo neurotóxico y se supone que el daño es acumulativo y, en la mayoría de los casos, de carácter irreversible ${ }^{4}$.

Los niños que presentan estas deficiencias, tienden a manifestar características tales como bajo nivel de atención, dificultad con las relaciones sociales, irritabilidad, trastornos del sueño, retraso de lenguaje, trastornos alimentarios, trastornos digestivos y regresión o pérdida de habilidades y conductas previamente adquiridas.

En Estados Unidos se practican análisis de 
ácidos orgánicos que incluirían más elementos en estudio que los perfiles metabólicos que se realizan en la mayoría de los demás países. Por esta razón es que muchas organizaciones de padres de niños autistas y especialistas recomiendan la aplicación de dietas de eliminación, las que se cree pudieran ser de mucha ayuda en el manejo terapéutico de la población afectada (ver dietas de eliminación). Es importante recordar que todos nosotros presentamos niveles de intoxicación similares, pero podría entonces existir una mayor fragilidad en los niños con TDD para efectos de eliminar toxinas, recuperarse de los daños o metabolizar los alimentos dañinos.

\section{Alergias e Intolerancia Alimenticias}

Rimland (1978), Sattock (1997), Shaw (1998), otros ${ }^{1-5}$ y organizaciones como el laboratorio Great Plains (EE.UU.) han señalado que muchos niños del espectro autista presentan alergias, intolerancia o hipersensibilidad a diversos alimentos, incluyendo los colorantes de dulces y diversos productos de fantasía, los cuales provocan una serie de alteraciones intestinales, manifestaciones cutáneas y fiebres inexplicables, entre otras. También se han descrito alteraciones de las estructura del intestino, similares a la de los celíacos, en un alto porcentaje de casos, según informan algunos autores ${ }^{2,4}$.

Tales alteraciones tendrían efectos que se relacionan a su vez con problemas conductuales, irritación y llanto inmotivado, problemas de atención o autoagresión. Habría que correlacionar estas hipótesis con el tipo de conducta que presentan las personas que padecen de enfermedad celíaca o intolerancia alimenticia. La mayoría de los niños con enfermedad celíaca y/o alergias alimentarias no presentan alteraciones conductuales de ningún tipo. En particular la alergia alimentaria a leche de vaca (la forma más frecuente de alergia alimentaria en la infancia) es una enfermedad transitoria, de inicio en los primeros meses de vida y con resolución entre los 1 y 3 años en la enorme mayoría de los niños).

Muchos niños con TDD presentan características compatibles con la enfermedad celíaca tipo I y II, con diarreas frecuentes, cóli- cas, retraso en el crecimiento e irritabilidad. También existe la misma condición tipo III, no siempre diagnosticada clínicamente y con los mismos síntomas, de forma más atenuada, de hecho, muchos niños y adultos presentan alteraciones gastrointestinales parecidas y no tienen rasgos autistas.

Si pensamos en un niño con dificultades de comunicación que siente dolores (cólicos, picazón, cefalea) o molestias que no puede comprender o explicar a nadie, podemos hacernos una idea de que, muchas veces, la única forma de expresar tales molestias la constituye el llanto, la agresión, la autoagresión o la necesidad de aislamiento.

Por estas razones, las instituciones, especialistas y sociedades mencionadas, sugieren eliminar colorantes de la dieta de los niños. Junto con esto, también se efectúan exámenes para determinar las probables alergias o intolerancias a fin de disminuir las reacciones adversas de los alimentos y, con ello, muchos de los problemas conductuales asociados. Los niños autistas no tienen menos frecuencia de enfermedades digestivas comparadas con niños sin autismo, por tanto, el desafío es diagnosticar dichas enfermedades para disminuir la sintomatología propia de ellas.

\section{Infecciones por hongos o bacterias y flora intestinal}

La flora intestinal contiene un sinnúmero de microorganismos cuya acción permite no sólo la degradación de alimentos y absorción de nutrientes, sino que además, se constituyen en una importante barrera inmunológica.

Las dietas ricas en carbohidratos simples (masas blancas, galletas, pasteles, etc), dulces, colorantes y bebidas de fantasía, frecuentemente se asocian al aumento de hongos, levaduras ${ }^{8}$ y bacterias en el tracto digestivo (Cándida Albicans, clostridia, Helycobacter pylori, entre otras). Una gran cantidad de productos alimenticios se obtienen de la fermentación de los alimentos por hongos (por ej: pan, vinagre, chocolate), los que a su vez generan una serie de toxinas que muchos de los niños con trastornos del desarrollo no son capaces de eliminar ${ }^{2,4,6}$.

Junto con lo anterior, la acción de hongos, levaduras y bacterias, deteriora no sólo la flo- 
ra bacteriana, sino que además debilitan el sistema inmune y hacen que las paredes intestinales se vuelvan más permeables al paso de diversas sustancias nocivas, que no han sido digeridas previamente. Entre estas se encuentran las exorfinas descritas anteriormente, por lo que frecuentemente los problemas asociados a la ingesta de gluten y caseína, se asociarían a la presencia de infecciones del tracto digestivo.

Estudios de los autores mencionados anteriormente, señalan que una gran cantidad de niños dentro del espectro autista, han sufrido de frecuentes infecciones respiratorias o al oído, siendo tratados con antibióticos orales, muchas veces de manera recurrente. Esto podría contribuir a una disminución de la flora bacteriana intestinal (por la acción no selectiva de los medicamentos) y al incremento de las infecciones descritas ${ }^{7,8}$.

Por tal razón, muchas de las investigaciones recomiendan administrar los antibióticos a través de inyecciones, para evitar el daño a la flora bacteriana. De no ser así, se sugiere complementar los tratamientos de las infecciones respiratorias y de las otitis, con la administración de probióticos (lactobacilos sin caseína) a fin de regular la presencia de microorganismos útiles en el tracto digestivo de los niños. Cabe mencionar que niños sin autismo también reciben tratamientos antibióticos en forma recurrente por auto indicación y con los efectos propios del uso de antibióticos sin justificación. Los efectos de la automedicación en los TDD no han sido investigados, pero es probable que exista una alta cantidad de niños con efectos secundarios derivados de tales prácticas y que alteran aun más la dinámica digestiva, conductual y por ende, la calidad de vida.

Un aspecto que se asocia frecuentemente a estas alteraciones, tiene relación con la presencia constante de heces blandas, con rastros de comida sin digerir. También es posible apreciar heces de color, lo que se asocia a reacciones alérgicas frente a colorantes. La mantención de dificultades para digerir y asimilar alimentos, se acompaña de bajo peso, a pesar de que las familias reportan que los niños comen de manera habitual, lo que a su vez causa gran extrañeza a los padres 9 .
En cuanto a las manifestaciones clínicas de los trastornos digestivos, Leny González ${ }^{4}$ lo resume de la siguiente forma:

"La historia clínica evidencia antecedentes de cólico abdominal y trastornos del sueño en la etapa de lactante menor, historia de infecciones bacterianas, virales, parasitarias y micóticas, hipersensibilidad a los sonidos, luz, sabores, olores y a las etiquetas de la ropa. Hay historia de alergia al gluten y caseína así como a múltiples alimentos.

Los niños autistas presentan con frecuencia síntomas digestivos y extradigestivos. Los síntomas digestivos incluyen dolor abdominal, pirosis, diarrea crónica, flatulencia, sialorrea, vómitos, regurgitaciones, pérdida de peso, rumiación, bruxismo, irritabilidad, disentería, estreñimiento e impactación fecal. En los períodos de irritabilidad, se observa insomnio y conductas autoagresivas; estas últimas reacciones descritas se han interpretado como parte de las alteraciones del neurodesarrollo y no como manifestación clínica de enfermedad gastrointestinal. En cuanto a los síntomas extradigestivos están los trastornos respiratorios, neurológicos y dermatológicos, por ejemplo, infección de las vías respiratorias superiores, en piel hay rash, eczemas, dermatitis atópica y prurito.

Los signos clínicos más comunes son: pliegue infraorbitario de Dennie Morgan, bolsas negras bajo los ojos, pestañas largas, distensión abdominal, halitosis, eritema perianal, fisura anal, piel reseca, queilosis angular y rinorrea anterior. También hay alteraciones en las características de las heces en la consistencia, color, olor, presencia de moco o sangre, restos alimentarios y grasa visible (para ver los exámenes recomendados a efectos de descartar las diversas patologías asociadas, se sugiere ver el artículo citado en la bibliografía).

Algunos tratamientos efectivos se refieren al uso de antimicóticos tales como la nistatina, aceite de orégano u otros, y siempre asociados a dietas sin levaduras, con el propósito de regular los aspectos descritos. Se han descrito algunos efectos nocivos o reacciones conductuales (irritabilidad, regresiones, cefaleas, etc) al inicio de tales tratamientos, los que estarían asociados a las toxinas de- 
rivadas de la muerte de los agentes patógenos. Tales manifestaciones disminuyen y desaparecen, a medida que se continúa con la terapia antimicótica y la dieta.

Una vez más, los estudios poblacionales dejan caer sombras de duda sobre estas hipótesis, ya que una alta población (sobre todo de mujeres) presenta infecciones intestinales por hongos o cándida, sin tener manifestaciones conductuales o afectivas relacionadas con tales afecciones, a la manera de los autistas, SDAH o cualquiera de los trastornos descritos.

Un último aspecto a considerar, se refiere a los hallazgos que relacionan la salud intestinal con la producción de serotonina y hormona neuro trófica, fundamentales para el desarrollo cerebral, el aprendizaje, la atención, el sueño y el desarrollo emocional, por lo que cualquier interferencia en el sistema digestivo debe ser tratada para eliminar importantes agravantes en el desarrollo de estos niños ${ }^{4}$.

\section{Vacunas}

Existe una gran controversia en Europa y EE.UU. por la utilización de derivados del mercurio (timerosal) en la preservación de las vacunas. La cantidad de vacunas que se administra a los niños, ha sido asociada con altos niveles de mercurio, los que a su vez estaría a la base de una verdadera "epidemia" de autismo en muchos de los países donde se han conducido investigaciones acerca del tema (EE. UU., Suecia, Dinamarca, Inglaterra). Desde hace mucho tiempo se conocen los efectos nocivos del mercurio y el daño neurológico que este tóxico provoca. Más aún, desde Junio de 2005 , el senado norteamericano se encuentra investigando los efectos descritos por cinco estudios epidemiológicos, avalados por instituciones tales como la FDA (Food and Drug Administration) La OMS (Organización Mundial de la Salud) y el Centro de Control de Enfermedades de Atlanta (CDC) a cargo del epidemiólogo Tom Verstraeten ${ }^{11-15}$.

Esto ha llevado a la eliminación del uso del timerosal en las vacunas, aun cuando existe la posibilidad que tal sustancia se siga utilizando el países en desarrollo, por lo cual es importante conocer el tipo de vacunas que se está administrando a los niños, o las vacunas alternativas con las que cuentan los distintos laboratorios o centros de atención.

Es importante señalar que trastornos como el autismo han aumentado en los últimos años, aunque la cantidad de vacunas es la misma que se aplica hace casi treinta años, por lo que no existe una relación directa de aumento de vacunas y autismo. Muchas veces los síntomas posteriores a una vacuna, pueden asociarse a fenómenos dentro del desarrollo esperable del niño. Por ejemplo, al aumentar la complejidad social exigida a los 2-3 años, aumenta la irritabilidad o desconexión de los niños. También el crecimiento cerebral altera el desarrollo cognitivo y hace que algunos casos pierdan funciones que no estaban totalmente establecidas. Hay niños quienes literalmente se desconectan a ciertas edades, lo que en muchos casos se debe a fallas que ya estaban "programadas" para ocurrir una vez que el cerebro llega a cierto tamaño.

Estudios de seguimiento muestran que la exposición al timerosal, cuando menos guarda relación con importantes reacciones alérgicas de contacto (dermatológicas), junto con recomendar que se disminuya la exposición de los niños a dicho preservante en vista de lo perjudicial de la acumulación de tal sustancia en los primeros 6 meses de vida, por la demostrada capacidad de producir alteraciones neurológicas y cardíacas (subtle neurological disorders $)^{11-15}$.

Investigaciones señalan muy poca relación entre la aplicación de vacunas y trastornos del desarrollo, aunque ya existe al menos un caso en EE.UU., en que se ha fallado a favor de una familia que informó cambios conductuales negativos, con posterior diagnóstico de autismo infantil, luego del proceso de vacunas dentro de los primeros dos años de vida de su hijo. No es claro que el timerosal provoque directamente autismo, debido a que esta es una condición multifactorial, junto con el hecho de que no es posible predecir el daño que ocasionará el mercurio en cada sujeto afectado. Sin embargo, se ha descubierto mayores concentraciones de mercurio en niños autistas, lo que indicaría una menor capacidad para eliminar estos tóxicos del sistema y por tanto ser una condición de riesgo frente a la exposición continuada al 
mercurio (hay que recordar que de eliminar el timerosal de las vacunas en los 12 primeros meses se reduce hasta un 50\% la exposición a mercurio durante el primer año ${ }^{12,13}$.

Por las razones expuestas, es respetable la preocupación y temor de las familias frente a la posible susceptibilidad genética a sufrir daño por exposiciones al mercurio de las vacunas. En muchos países, el sistema privado tiene disponibilidad de vacunas sin timerosal, que deben ser pagadas por las familias, ya que no todos los países compran vacunas libres de mercurio para el sistema público obligatorio.

Una alternativa, es espaciar las vacunas y dosis para disminuir la exposición frecuente a ciertas cantidades de mercurio, en períodos tan cortos de tiempo, que en ocasiones implica más de una dosis en una semana o mes. Otra, es solicitar la aplicación de vacunas sin timerosal (más caras) y cubrir personalmente los costos de tal procedimiento.

Muchas familias han optado por no vacunar a sus niños, pero ningún estudio se ha realizado para determinar si sus hijos realmente se constituyen como una población más afectada por las enfermedades que están dentro de los programas de vacunación. Como padres, siempre se quiere proteger a los hijos, pero es imprescindible informarse y exigir a la comunidad médica tal información de manera clara y confiable.

\section{Dietas de Eliminación}

Los aspectos fundamentales de las dietas de eliminación, se refieren a evitar el daño que muchos de los alimentos descritos producirían en los niños con trastornos del desarrollo. Su uso ha sido muy difundido en países tales como Canadá, México, Venezuela, Estados Unidos, Inglaterra, entre otros.

Es importante señalar que aún no existe un cúmulo de investigaciones que permita afirmar fehacientemente la utilidad de tales procedimientos, no obstante, el reporte de familias, asociaciones de padres de niños con trastornos del desarrollo e importantes especialistas, se refieren a que una gran cantidad de niños se habrían beneficiado con tales intervenciones. En general, se señala que mejoran la atención, la capacidad de vincularse y la intencionalidad comunicativa, a la vez que disminuyen el comportamiento agresivo o auto agresivo, el llanto inmotivado o impredecible y manifestaciones como estereotipias o movimiento constante.

Es importante destacar que la mayoría de los textos y reportes que se refieren de modo más serio al tratamiento en cuestión, mencionan que no debe considerarse este como una alternativa opuesta a los tratamientos médicos. Tampoco debe considerarse como la solución final al problema, puesto que a pesar de que muchos de los síntomas cognitivos y conductuales tiendan a disminuir, la casi totalidad de los niños mantiene su diagnóstico y sigue necesitando de terapia psicoeducativa y lingüística para mejorar los diversos aspectos de su desarrollo social y académico.

$\mathrm{Al}$ respecto es posible recordar lo que menciona Lorna Wing ${ }^{16}$, respecto a que no se debe considerar patología como el autismo (x frágil, Sotos, Angelman, etc), dentro de la visión de un niño normal atrapado en una esfera de cristal, que será totalmente liberado una vez que ésta se rompa. Un trastorno del desarrollo implica diferencias metabólicas y, por tanto, genéticas, las cuales acompañarán al sujeto por toda su vida. La investigación y la terapia tienen mucho que descubrir aún, para poder ofrecer mejores alternativas de adaptación y desarrollo a esta población.

Junto con la escasez de estudios poblacionales, las dietas de eliminación son de difícil aplicación, sobre todo cuando los niños pueden verse afectados por muchos alimentos (alergias, adicciones, intolerancias). Esto hace que todo el grupo familiar deba adoptar un nuevo estilo alimentario y de vida, para favorecer el desarrollo más adecuado de uno de sus integrantes. La demora para preparar comidas alternativas, la dificultad para encontrar los alimentos prescritos y la dificultad para cambiar los hábitos familiares dificultan de gran manera el seguimiento correcto de tales dietas.

Otro aspecto importante se refiere a que muchos de los elementos a eliminar tardan en salir del organismo en semanas o meses, por lo que la dieta debiera hacerse por al menos 3 ó 6 meses. Muchas personas abandonan la dieta si 
al año no hay logros, aunque muchos lo hacen más temprano.

Teniendo en cuenta las consideraciones previas, se puede sugerir una dieta de eliminación cada vez que existan sospechas o antecedentes que orienten hacia reacciones alérgicas, preferencias excesivas y cambios de comportamiento asociados con la ingesta de determinados alimentos.

A modo de síntesis, podríamos señalar algunos signos que permiten sugerir una dieta de eliminación: alergias e intolerancias alimentarias, cambios de comportamiento asociados a ingesta o cambio de alimentos, trastorno de sueño asociado a alimentación, regresiones comportamentales o afectiva, preferencia excesiva por ciertos alimentos (lácteos, masas de trigo, centeno o avena), exceso de sed, sudoración, pigmentación de la piel y olor extraño (corporal o en la orina); antecedentes familiares de enfermedades metabólicas, enfermedad celíaca o trastornos del desarrollo, heces blandas o con comida sin digerir (asociadas a cambio de dieta o que se mantienen en el tiempo) y bajo peso a pesar de mantener una ingesta alimenticia.

Aunque la dieta de eliminación excluye los alimentos que contienen proteínas del gluten, caseína, colorantes y preservante que producen alteraciones de la conducta y otras ya mencionadas por su efecto neurotóxico en el organismo, su objetivo principal como en cualquier alimentación, es promover el crecimiento y desarrollo del niño, mantener el estado de nutrición normal, sin carencias específicas. Por lo tanto, si la dieta no fuera lo suficientemente variada por existir alergias, rechazo o mucha intolerancia a diversos alimentos, ameritará el suplemento de vitaminas y minerales si es preciso, para evitar estos déficits.

Por último, es importante recordar, que un procedimiento como el que se describe, debe ser realizado bajo la supervisión de especialistas, tales como el médico tratante (psiquiatra, neurólogo, pediatra) y nutricionista o nutriólogo (a). Toda intervención biológica, como es en este caso la eliminación de ciertos alimentos, debe ser revisada permanentemente, para que no existan deficiencias nutricionales que afecten el desarrollo de los niños.
Más aun, antes de comenzar una dieta de eliminación, es preferible consultar un gastroenterólogo especializado en trastornos del desarrollo, para determinar si nuestro hijo o hija presenta problemas de absorción (enfermedad celíaca, permeabilidad intestinal) presencia de cándida o de hongos y exámenes sanguíneos para determinar alergias o intolerancias alimentarias (algunas con base genética como las intolerancias a la lactosa o al gluten).

En mi práctica profesional, tiendo a recomendar estos últimos exámenes, porque muchas veces los niños sujetos a dietas libres de caseína y gluten, se benefician, no porque presenten adicción o efectos de los opiáceos, sino porque son celíacos (por ejemplo en Chile más del $40 \%$ de sus habitantes presenta la enfermedad celíaca tipo I o II) o intolerantes a la lactosa (según sean indoeuropeos o de origen amerindio, la intolerancia se presenta entre un 20 y un $90 \%$ respectivamente). Tales afecciones producen hinchazón abdominal, meteorismo, gastritis, problemas para evacuar, etc, los que causan mucha molestia y ansiedad, alterando el ánimo y la conducta.

El realizar los exámenes señalados justificaría hacer o no una dieta, en lugar de intentar estos procedimientos sólo por el hecho de que han sido recomendados por familias o en páginas de internet.

\section{Tóxicos ambientales}

La contaminación ambiental ha sido otro de los posibles culpables propuestos como causa de los trastornos del desarrollo. El aumento de metales tóxicos como el plomo, el aluminio, el mercurio y otros, ha llegado a grados críticos, sobre todo en nuestro continente. En países como Brasil, se recomienda no consumir la cáscara de ciertas hortalizas, debido a la contaminación por agro tóxicos, neumáticos y sus desechos, pesticidas, etc. Esta situación también se encuentra en el mar, por lo que a las embarazadas se les aconseja no consumir peces grandes, como el atún, para prevenir problemas en la gestación.

Es claro que los tóxicos ambientales producen serios daños a la salud y deterioran el 
sistema nervioso. Lo que no es posible determinar es el tipo de daño, la magnitud ni la evolución de estos, en las distintas etapas de la gestación o la vida de un niño.

Procedimientos como la quelación, destinados a la eliminación de tóxicos o la cámara hiperbárica, no cuentan aún con evidencia que sustente el gasto económico y de tiempo que estos procedimientos implican. Así como las comunidades de padres informan de curas casi milagrosas, los estudios realizados ${ }^{17}$ señalan una casi total ineficiencia y, en muchos casos, reacciones alérgicas bastante severas.

He leído de casos que señalan grandes progresos al utilizar estas estrategias. Sin embargo, los que yo he visto, no me convencen de las maravillas que se proponen. También, al consultar las investigaciones al respecto, no se encuentra mayor apoyo a tales prácticas. Muchas veces los llamados milagros pueden corresponder a casos mal diagnosticados en un inicio o a niños que a pesar del cuadro, tenían un muy buen potencial y se beneficiaron de todas las terapias hechas (conductuales y educativas) que se realizaron junto con las intervenciones biológicas y dietas ${ }^{18,19}$.

Nuevamente, nos encontramos ante el hecho de que eliminar tóxicos puede ayudar a nuestro hijos a disminuir algunas conductas disruptivas o incrementar niveles de atención, pero no sabemos realmente la relación de tales sucesos, ni podemos predecir la magnitud de los avances o el tiempo en que pueden aparecer. Muchas veces no veremos avance alguno.

\section{Consideraciones críticas}

Sin embargo, hasta la fecha los estudios más importantes, con mejor diseño metodológico y aprobado en las publicaciones más serias, no han podido demostrar que el gluten y la caseína tengan el efecto propuesto. Tampoco se ha encontrado un alto nivel de tales proteínas en la orina de niños afectados con autismo, SDAH u otros trastornos del desarrollo para justificar las hipótesis de Rimland y otros. De la misma manera, se ha evaluado la efectividad de las dietas de eliminación y no se ha encontrado mayores avances o progresos en las poblaciones estudiadas. Cuando se ha utilizado observadores independientes (que no sean padres o los clínicos de cada niño) estos no han podido señalar cambios significativos.

Si usted busca en las revistas especializadas, con comités editoriales de excelencia y alto grado de corrección metodológica (por ejemplo a través de www.scholar.google.com, Proquest, etc), encontrará más artículos que muestran pocos avances y evidencias a favor de los tratamientos biológicos, que a favor.

Es importante detenerse a considerar la necesidad de pruebas o evidencia de estudios metodológicamente bien realizados. Los aspectos básicos de un buen estudio, son que cumpla al menos las siguientes condiciones: una muestra significativa de sujetos, claridad y objetividad en el diagnóstico inicial, utilizar observadores independientes a la familia y los especialistas, utilizar grupos de tratamiento y grupos de control, utilizar procedimientos tales como el placebo, utilizar técnicas de "doble ciego" y utilizar análisis cualitativo y estadístico.

Una gran cantidad de sistemas o alternativas de terapia han sido rechazadas por las investigaciones (ver el caso de la comunicación facilitada) que demostraron errores en los informes que describían resultados positivos, que no se replican en posteriores estudios (consulte en internet los artículos sugeridos al final del capítulo). En la actualidad, incluso el análisis de los trabajos de Lovaas en autismo, aplicar ABA (Applied Behavior Analysis) han sido cuestionados debido a problemas en la selección de la muestra (autismo atípico, de alto rendimiento o sin diagnóstico claro) que han hecho imposible replicar los mismos resulta$\operatorname{dos}^{17-20}$. Lo mismo sucede con terapias florales, estimulación auditiva, integración sensorial y otras formas de terapia, cuyos resultados, positivos en unas primeras investigaciones, no han podido ser replicadas hasta ahora, lo cual hace que no puedan ser consideradas como "curas" o tratamientos altamente efectivos.

Revisando las investigaciones acerca de suplementos tales como la taurina, secretina y otros, las investigaciones mejor desarrolladas concluyen que no existen diferencias significativas entre los niños que son suplementados y aquellos que no lo son.

Lo que si puede recomendarse, pero bá- 
sicamente porque se ha comprobado que es beneficioso para casi cualquier persona, es el consumo de suplementos vitamínicos de complejo B junto con magnesio, suplemento de omega 3-6-9, lactobacilos y dietas que tengan poca azúcar refinada, con poco colorante y preservante y que sean ricas en fibra. Sin embargo, no existe evidencia de que tales compuestos "mejoren" a los niños, en el sentido en que algunos padres y profesionales (no investigadores) creen o afirman. No quiero desanimar a nadie a no intentar todo por sus hijos, pero como clínico no puedo recomendar lo que no está apoyado por evidencia fuerte. Yo mismo he probado con nuestro hijo dietas y suplementos, sin mayores resultados, como también ha acontecido a la mayoría de mis pacientes durante más de 25 años.

Muchas de las dietas y suplementos se aplican luego de que han fallado otras terapias, o cuando los avances son lentos hacia los tres o seis años. Sin embargo, desde la neurociencia, sabemos que a esas edades se producen diversos fenómenos en el cerebro, tales como la muerte de neuronas (programada) a nivel de lóbulos frontales, lo que los hace más eficientes y favorece un mayor control, más lenguaje y más adecuación conductual. También, existe una maduración del sistema dopaminérgico, que permite un mayor control de la impulsividad, mejora la atención y la memoria.

Por estas razones, tanto los niños normales, como los que presentan algún trastorno, tienden a manifestar cambios positivos a ciertas edades, sin que tengan necesaria relación con lo que los adultos creen. El problema está en que los humanos tendemos a relacionar eventos que se presentan al mismo tiempo, por lo cual "descubrimos" relaciones donde no necesariamente existen.

Tome por ejemplo la situación típica del embarazo de una mamá de un niño que no habla ni comprende el lenguaje. Al mismo tiempo, este pequeño comienza a estar más irritado. La primera idea que los padres tienen es que el pequeño está celoso del hermano que viene. La maternidad es un concepto lingüístico complejo y mal puede un niño con poco lenguaje comprenderlo. Si dejamos de interpretar y observamos adecuadamente, pode- mos ver que los padres están más ansiosos por el embarazo y que el niño está respondiendo a esto, o a una alergia o al cambio de horario. Que dos fenómenos ocurran en un mismo tiempo, no implica que tengan una relación de causa efecto. Piense en todas las veces en que las parejas discuten por malentendidos que surgen de haber creído en asociaciones que no son correctas.

Muchas investigaciones han señalado que el cambio descrito por dietas $u$ otros tratamientos alternativos, se deben simplemente a que comenzaron a aplicarse poco antes de saltos madurativos en los niños. Por esto es importante exigir estudios validados, confiables que aporten evidencia fuerte antes de comenzar cruzadas terapéuticas que no tienen una base sólida.

Quiero insistir en que hay casos en los que parece funcionar la aplicación de los tratamientos biológicos (no en mi experiencia), pero la ausencia de estudios críticos y bien diseñados me hace guardar reservas al momento de responder a los padres si deben o no aplicar tales tratamientos. Mi respuesta generalmente es: háganlo, pero estas son las evidencias en contra y estas pocas, a favor.

Los padres siempre intentarán todo por sus hijos, lo único que pido es que se informen con más de una fuente. Donde no existan estudios validados, donde se recomienden productos de un solo laboratorio, donde los investigadores son parte de tales laboratorios, es sano sospechar. Incluso, me atrevo a señalar, que donde quienes proponen estas alternativas terapéuticas no aceptan discutir en congresos o reuniones clínicas con especialistas, también debiera sospecharse de la real efectividad de tales alternativas.

Si bien es posible constatar que las dietas de eliminación han comenzado a tener aceptación y a ser un foco de atención en distintas partes del mundo, la evidencia metodológica no parece avalar con estudios poblacionales, epidemiológicos ni medicina basada en la evidencia (meta análisis) tales postulados.

La bibliografía consultada muestra estudios en poblaciones muy reducidas o particulares, con el aval del testimonio de las familias. Sin embargo, desde un punto de vista estricta- 
mente metodológico, no podemos considerar lo testimonial como evidencia científica.

Las críticas fundamentales a esta propuesta terapéutica y a muchas publicaciones relacionadas, de organizaciones para combatir el autismo o el déficit atencional, pueden resumirse en los siguientes puntos.

La falta de estudios con fuerte diseño metodológico, realizados en poblaciones estadísticamente significativa que avalen, tanto la propuesta de análisis de los TPD, como el curso de tratamiento; la falta de estudios con diseños adecuados que muestren de modo preciso la evolución de los casos y su relación con el tratamiento biológico; la dificultad para la realización de exámenes completos y la falta de evidencia estadística o metodológica que avale la relación con TPD; el exceso de testimonios no especializados (familias, terceros) que se utilizan para avalar los resultados terapéuticos, y la tendencia, en algunas organizaciones de padres, testimonios y publicaciones, a considerar los tratamientos biológicos como la solución final a los cuadros (excepción de las publicaciones de Leticia Domínguez y Bruce Semon $)^{21,22,24}$, lo que parece promover una evitación de los tratamientos farmacológicos y psicoeducativos.

Lo que muestran los estudios y la experiencia clínica, es que los tratamientos biológicos (ya sea por los efectos asignados o por el cambio en la percepción de los padres que los aplican), en ocasiones favorecen la disminución de conductas disruptivas relacionadas con problemas gastrointestinales, con lo que serían un apoyo dentro de un plan general de terapia. Lo que se discute es que sean promovidos como causa de los trastornos (estos son multicausales) y como cura de los mismos.

La dilatada investigación en relación a la farmacoterapia, la rehabilitación psicoeducativa y la terapia de familias con niños con TPD, presenta un mayor apoyo en términos de diseños de estudios, evidencia y análisis estadístico o de contenido. Por esta razón, en caso de elegir la realización de un tratamiento biológico, es imprescindible continuar con las terapias que ya han probado su efectividad y que tiene una historia de investigación seria en el tema ${ }^{11}$.
Es claro, dentro de los principios de bioética, que las familias deben participar en el diseño e implementación de terapias para sus hijos/as (principio de autonomía), para lo cual es necesario que los especialistas les informen acerca de las principales líneas terapéuticas actuales, para que, sea posible intervenir de manera compleja, en equipo y realizando un trabajo compartido, en pos de la recuperación e inclusión de los niños afectados.

Hasta la fecha, aún con ciertos reparos, los estudios muestran una mayor efectividad en la combinación de estrategias, uniendo el apoyo farmacológico adecuado, con modificación de conducta y trabajo educativo.

\section{Conclusiones}

La revisión bibliográfica del tema, aporta más evidencia en contra de la utilidad de los tratamientos biológicos, sobre todo debido a la debilidad metodológica de los estudios a favor, la cuestionable base teórica de los postulados y el exceso de reportes anecdóticos y familiares de los beneficios de tales prácticas.

Las deficiencias metodológicas de los estudios favorables, no permiten generalizar resultados, establecer correlaciones causales, diferenciar los cambios de conducta de las manifestaciones propias del neurodesarrollo en niños (poda neuronal, procesos de maduración, etc) ni aislar variables interferentes (otras terapias, estilo familiar, educación).

No es claro aún si en los casos reportados de niños beneficiados con dietas libres de gluten y caseína, reducen manifestaciones conductuales por no estar expuestos a tales proteínas, o por el hecho de ser celíacos o intolerantes a la lactosa.

Para el caso del timerosal, aun cuando no se ha comprobado una relación directa con el autismo, si existe numerosa evidencia causal en relación a trastornos neurológicos, asma y problemas cardíacos, lo que ha llevado a que sea retirado de las vacunas infantiles en los países desarrollados.

La presencia de tóxicos ambientales constituye un riesgo evidente y probado para el neuro desarrollo infantil, aunque no es claro 
el tipo de trastornos resultantes. Los procedimientos de quelación y eliminación de tóxicos no cuentan aun con investigaciones que comprueben su utilidad en la mejoría de los trastornos del desarrollo.

Finalmente, los estudios realizados con muestras de importancia y metodología más rigurosa, no permiten relacionar el uso de los tratamientos biológicos con mejorías y avances sustanciales en la conducta de niños con trastorno del desarrollo ${ }^{24,25}$.

\section{Referencias}

1.- Rimland B: Nutrition in: The Treatment of Autistic Children. Ponencia presentada en el I simposio Internacional de Autismo. Madrid. 1978.

2.- Shattock P, Savery D: El Autismo como Trastorno metabólico En: Riviere A, Martos J: El tratamiento del autismo. Nuevas Perspectivas. Ministerio del Trabajo y Asuntos Sociales. España. 1997.

3.- Shaw W: Tratamientos Biológicos del Autismo y PDD. Grat Plañís Laboratory. Kansas. USA. 1998.

4.- González Lenny G: Manifestaciones gastrointestinales en trastornos del espectro autista. Revista Colombia Médica 2005; 36 (2, s1): 36-8.

5.- Cervera Renut C: Candidiasis Crónica, parte II. Revista Especializada de Nutrición. Renut 2005; Año 1, $\mathrm{N}^{\circ}$ 3.

6.- Enfermedad Celíaca. Fundación Celíaca. Argentina FUNCEL 1986.

7.- Fundación Paso a Paso: Aspectos Dietéticos para autistas. Pág 1-10, febrero, 2002.

8.- Henríquez G: Evaluación del estado Nutricional en Centro Nutricional Infantil de Antemano. 1999. Caracas. págs. 17- 62 .

9.- Longo EN, Navarro E: Técnica Dietoterápica en las enfermedades Intestinales Capítulo 5 Ed. El Ateneo, 1997, pág. 114

10.- Rietschel RL, Adams RM: Reactions to thimerosal in hepatitis B vaccines. Dermatol Clin 1990; 8 (1): 161-4.

11.- Bigham M: Thiomersal in Vaccines: Balancing the Risk of Adverse Effects with the Risk of VaccinePreventable Disease Drug Safety 2005; 28 (2): 89-101.

12.- Geier M, Geier D: Thimerosal in Childhood Vaccines, Neurodevelopment Disorders, andHeart Disease in the United States. Journal of American Physicians and Surgeons 2006; 8 (1): 5-11.

13.- Ball LK, Ball R, Pratt R: An Assessment of Thimerosal
Use in Childhood Vaccines. Pediatrics 2001; 107 (5): 1147-54

14.- Geier M, Geier D: Neurodevelopmental Disorders after Thimerosal-Containing Vaccines: A Brief Communication. Experimental Biology and Medicine 2003; 228: 660-4.

15.- Maya L, Luna F: El timerosal y las enfermedades del desarrollo infantil. Anales de la facultad de Medicina. Universidad de Nacional Mayor San Marcos. 2006; pp. 225-74. Lima.

16.- Wing L, Everad M: Autismo Infantil. Aula XXI. Santillana. España. 1982.

17.- Harrison Elder J: Current Treatment in Autism. Examining Scientific evidence and clinical implications. Journal of Neuroscience Nursing 2002; 43 (2): 67-73.

18.- Cormier E, Harrison Elder J: Diet and Child Behavior Problems: Fact or Fiction?. Pediatric Nursing 2007; 33 (2): 138-43.

19.- Calderón-González R, Calderón-Sepúlveda F: Terapias sin base científica empleadas en el manejo de los Trastornos del Neurodesarrollo. Revista Mexicana de Neurociencia 2001; 2 (4): 223-30.

20.- Morant A, Mulas F, Hernández S: Bases neurobiológicas del Autismo. Revista Neurología Clínica 2001; 2 (1): 163-71.

21.- Negrón R, Lilia T: Hallazgos Clínicos y Bioquímicos en una muestra de 100 Niños Autistas de Venezuela. Ponencia presentada en International Symposium on Autism Research, Boston, Mass, Julio 14-18. 1981.

22.- Reichelt KL: Gluten, Milk Proteins and Autism: Dietary Intervention effects on Behaviour and Peptide Secretion. Journal of Applied Nutrition 1990; Vol. 42, $\mathrm{N}^{\circ} 1$.

23.- Narbona J, Chevrie-Müller: El lenguaje del niño. Ed. Massón. Barcelona. 1997.

24.- Domínguez L: Aplicando los tratamientos biológicos del autismo y TDAH en casa, En: Shaw, William: Tratamientos Biológicos del Autismo y PDD. Grat Plañís Laboratory. Kansas. USA. 1998.

25.- Semon B: Tratando levaduras en niños con autismo En: Shaw, William: Tratamientos Biológicos del Autismo y PDD. Great Plains Laboratory. Kansas. USA. 1998.

26.- Riviere A, Martos J: El tratamiento del autismo. Nuevas Perspectivas. Ministerio del Trabajo y Asuntos Sociales. España. 1997.

27.- Wong H, Smith R: Patterns of Complementary and Alternative Medical Therapy Use in Children Diagnosed with Autism Spectrum Disorders. J Autism Dev Disord 2006; 36: 901-9. 